\title{
On Modeling the Volatility of Nigerian Stock Returns Using GARCH Models
}

\author{
C. E. Onwukwe (Corresponding author) \\ Department of Mathematics/Statistics and Comp. Science, University of Calabar \\ P.M.B. 1115, Calabar, Cross River State, Nigeria \\ E-mail: ceonwukwe@yahoo.com \\ B. E. E. Bassey \\ Joint Higher Degree Programme, National Mathematical Center, Kwali, Abuja \\ E-mail: benzebassika@yahoo.com \\ I. O. Isaac \\ Department of Mathematics/Statistics and Comp. Science, University of Calabar \\ P.M.B. 1115, Calabar, Cross River State, Nigeria \\ E-mail: idonggrace@yahoo.com
}

Received: June 13, 2011 Accepted: June 27, 2011 Published: November 1, 2011

doi:10.5539/jmr.v3n4p31 URL: http://dx.doi.org/10.5539/jmr.v3n4p31

\begin{abstract}
This study investigates the time series beaviour of daily stock returns of four firms listed in the Nigerian Stock Market from 2nd January, 2002 to 31st December, 2006, using three different models of heteroscedastic processes, namely: GARCH $(1,1)$, EGARCH $(1,1)$ and GJR-GARCH models respectively. The four firms whose share prices were used in this analysis are UBA, Unilever, Guiness and Mobil. All the return series exhibit leverage effect, leptokurtosis, volatility clustering and negative skewness, which are common to most economic financial time series. Except for Guiness, other series display significant level of second-order autocorrelation, satisfying covariance-stationary condition. These models were estimated assuming a Gaussian distribution using Brendt-Hall-Hall-Hausman (BHHH) algorithm's program in Eview software platform. The estimation results reveal that the GJR-GARCH $(1,1)$ gives better fit to the data and are found to be superior both in-sample and out-sample forecasts evaluation.
\end{abstract}

Keywords: GARCH, Models, Series, Volatility, Stock, Heteroscedasticity and Returns

\section{Introduction}

Financial markets are well known for their uncertainty, especially the irregularity in the behaviour of certain financial indices, such as stock prices, exchange or interest rates, government bonds, treasury bills and so on, that are prone to constant variability. Such variability, otherwise known as volatility can generate very high frequency series of random variables which are stochastic in nature, the dynamics of which can best be described by means of models.

Volatility permeates finance and it is a key variable used in many financial applications such as investment, portfolio construction, option pricing and hedging as well as market risk management. Good forecasts of volatility, therefore, become extremely important for making financial decisions. First, the knowledge of volatility could guide traders on the risk of holding an asset or the value of an option, and also provides reasonable forecasting confidence interval (Engle et al, 2005). Secondly, a reliable volatility model sheds further light on the data generating process of the returns (Hongyu and Zhichao, 2006). Thirdly, estimates of financial markets volatility may be the telescope of envisaging how robustness of the economy is and the direction of monetary and fiscal policies. These might be the reasons why volatility modeling has gained considerable popularity in literatures of financial engineering.

Many and diverse models by which volatility forecast can be achieved have been proposed, ranging from time series based volatility models such as exponential smoothening, Garman-Klass model, heteroscedasticity models such as ARCH, to options-implied volatility models such as the classical Black-Scholes equation to mention but a few. Their empirical performance has also been explored by data of several equity markets. Bollerslev (1986) used ARMA and EGARCH models to study the US stock from 1889 to 1990; Akigray (1989) employed GARCH (1,1), ARCH (2) and Exponentially 
Weighted Moving Average (EWMA) to detect the time series properties of USA stock return; McMillan and Gwilym (2000) used Random Walk, Moving Average, Exponential Smoothen (ES), EMWA, GARCH (1,1), TGARCH (1,1), EGARCH $(1,1)$ and FIGARCH $(1,1)$ for the Londons FTSE100; while Franses and Djik $(2000)$ used ARMA (0,1,1) process to model volatility of S and P 500 Index. Similarly, Udo (2000) compared the forecast capabilities of some linear with nonlinear models using data from Germany and American stock markets, just as Franses and Djik (1998) compared volatility forecasts of QGARCH $(1,1)$, GJR-GARCH $(1,1)$, GARCH $(1,1)$ and Random Walk Models for stock indices across Germany, Spain, Netherland, Italy, and Sweden. Finally, Haque et al (2004) did same for ten Middle East and African emerging markets using random-walk model, ARMA models and GARCH-M model.

As elegant as the specifications of these models may have appeared, many of them failed to capture much of the empirical evidence such as time varying variance, fat-tailness, volatility clustering and leverage effect. Probably the most widely used, but by no means the only such models are the family of heteroscedasticity models, where the conditional variance of the distribution is a direct function of previous information. This class of models has been extensively applied in numerous studies and researches ever since the Autoregressive Conditional Heteroscedasticity (ARCH) model was formulated by Engle (2001) and subsequently extended to the Generalized Autoregressive Conditional Heteroscedasticity (GARCH) model by Bollerslev (1986). Most of these findings were results of studies carried out in developed markets of advanced economies, little have been done about the Nigerian capital market. This study is done with a view to verifying if these findings are replicable in the Nigerian capital market. From the foregoing, therefore, this paper focuses on finding three fitting models among the family of the GARCH models namely: GARCH $(1,1)$, EGARCH $(1,1)$ and GJR GARCH $(1,1)$ using the daily data of five different equity quoted in the Nigerian Capital Market.

\section{Discussion}

Prior to the focus on heteroscedasticity the Autoregressive Integrated Moving Average (ARIMA) model of Box and Jenkins (1976) and Black and Scholes (1975) models were frequently used in empirical researches to investigate volatility of assets returns and option pricing (Poon and Granger, 2003; Haque et al, 2004). However, the two models were based on the wrong assumptions of constant variance. Lognormal distribution gave spurious results as they failed to capture some salient stylized facts of returns dynamics such as volatility clustering, leverage effect and leptokurtosis which are widely documented empirical evidence. Hence, the type of results they got. To account for this volatility clustering of financial return series, Engle (2001) proposed the Autoregressive Conditional Heteroscedasticity (ARCH) models. According to Engle (2001), in the mean equation of the ARCH model, the disturbance or innovation of a discrete time realvalued conditional heteroscedastic stochastic process $\left\{\varepsilon_{t}\right\}$ is defined as

$$
\varepsilon_{t}=z_{t} \sigma_{t}
$$

where $z_{t} \sim \operatorname{iid}(0,1)$ with

$$
E\left(z_{t}\right)=0 \text { and } \operatorname{Var}\left(z_{t}\right)=1 .
$$

And the conditional varianrce (volatility) is denoted by

$$
\operatorname{Var}\left(\frac{z_{t}}{\psi_{t-1}}\right)=\sigma_{t}^{2}=\omega+\sum_{i=1}^{p} \alpha_{i} \varepsilon_{t-p}^{2}
$$

with the following constraints: $\omega>0$ and $\alpha_{t} \geq 0$, meant to ensure that $\sigma_{t}^{2}$ is positive and $\psi_{t-1}$ is the information available at the time $t$ (usually the past values of $u_{t}$ ). Despite its success in addressing the above challenges, a lot of criticism trailed the ARCH specification, one of such weaknesses, Laurent and Peters (2002) noted, involves the tedious estimation of numerous parameters. This led to the generalized ARCH (GARCH) model of Bollerslev (1986), a more parsimonious representation in which the conditional variance depends simultaneously on the squared residuals and on its past value. The specification of the $\operatorname{GARCH}(\mathrm{q}, \mathrm{p})$ is as follows:

$$
\sigma_{t}^{2}=\omega+\sum_{i=1}^{q} \alpha_{i} \varepsilon_{t-i}^{2}+\sum_{j=1}^{p} \beta_{j} \sigma_{t-j}^{2}
$$

with the initial conditions: $\omega>0, \alpha_{i} \geq 0$ (for $i=1, \cdots, q$ ), $\beta_{j} \geq 0$ (for $j=1, \cdots, p$ ) and $\beta+\alpha<1$, to ensure that the conditional variance $\sigma_{t}$ is nonnegative.

The standard GARCH, otherwise specified as GARCH $(1,1)$ model is not without limitations. The model is not flexible because of the constraint conditions imposed on the parameters to guarantee a nonnegative result (Wagle, 2008). Secondly, the GARCH model fails to capture asymmetric response of the market as it could not distinguish different impacts of respective positive and negative shocks to volatility. This is contrary to known empirical evidence where current volatility is negatively correlated with past stock return. This phenomenon is otherwise referred to as leverage effect. 
To address the asymmetric response to positive and negative shocks, Nelson (1991) proposed an Exponential GARCH (EGARCH), Glosten and Runkle (1993) proposed the GJR-GARCH model, Zakoian (1994) proposed the threshold GARCH (TGARCH) model and Baillie and Mikkelsen (1996) introduced the fractional integrated GARCH (FIGARCH).

The EGARCH (p, q) model has the following specification:

$$
\ln \sigma_{t}^{2}=\omega+\sum_{i=1}^{p} \alpha_{i}\left[\lambda \varepsilon_{t-i}+\gamma\left\{\left|\varepsilon_{t-1}\right|-\sqrt{\frac{2}{\pi}}\right\}\right]+\sum_{j=1}^{q} \beta_{j} \ln \sigma_{t-j}^{2},
$$

where $E\left[\varepsilon_{t}\right]=\sqrt{\frac{2}{\pi}}$. This specification ensures that the conditional variance is always positive since it is expressed as a function of logarithm.

The GJR-GARCH (p, q) has the following specification:

$$
\sigma_{t}^{2}=\omega+\alpha \varepsilon_{t-1}^{2}+\beta \sigma_{t-1}^{2}+\phi \lambda_{t-1} \varepsilon_{t-1}^{2},
$$

where

$$
\lambda_{t-1}=\left\{\begin{array}{l}
1, \text { if } \varepsilon_{t-1}<0 \\
0, \text { if } \varepsilon_{t-1} \geq 0 .
\end{array}\right.
$$

There are very many different variants of the GARCH class of models with each successive one meant to account for some stylized facts (especially asymmetric and long memory phenomenon) deficient in the former. Franses and Djik (2000) and Bollerslev (1986) provide excellent glossary of the conditional heteroscedasticity models. Of all the volatility models found in literature, none has gained wider acceptance and popularity among research community as the GARCH models. The popularity of this model, Zhang and Wirjanto (2006) argued sterns from its ability to capture some dynamics of individual stock returns described above. A large pool of researchers affirmed that the standard GARCH $(1,1)$ model fits most financial time series well (Egert and Koubaa, 2004; Engle, 2001). Both developed and emerging economies stock markets have been objects of several investigations using the GARCH $(1,1)$ specifications as the benchmark model for their analyses (Hansen and Lunde, 2001; Engle and Patton, 2000; Engle, 2001). A study by Akigray (1989) used a GARCH $(1,1)$ model to investigate the time series properties of the stock returns and reported that the GARCH models are the best model in describing and forecasting S and P-500 stock index volatility. Ann-Sing and Mark (2005) even compared the empirical performances of the statistical projection models with BlackScholes and GARCH option pricing models and concluded that the GARCH models offers better pricing performances than the former.

Another study by Najand (2002) examines the relative ability of linear and nonlinear models to forecast the daily S and P 500 stock index volatility. The study finds that the nonlinear GARCH-M model performs better than the linear models, and best using the RMSE and MAPE statistical loss penalty functions. Ricardo (2000) employs the same procedures adopted by Najand (2002) using the Karachi Stock Exchange 100 index for the period of eight years spanning between 20012007 and also finds that GARCH $(1,1)$ - M model is most appropriate in fitting its empirical data.

Similarly, Poshakwale and Murinde (2001) and Egert and Koubaa (2004) analyzed the features of conditional variance in daily returns of stock market indices in the G-7 and six selected economies of Central and Eastern Europe (CEE) from 1987 to 2002. The estimated results reveal that stock returns from the G-7 can be equally modeled by the standard GARCH $(1,1)$ model. The model, however, failed to capture the empirical features of the Central and Eastern European markets. This is not a surprising result since Engle and $\mathrm{Ng}$ (1998) had experienced similar challenge in their bid to model the Japanese stock return data. The two instances clearly bring to bear one fundamental weakness of the standard GARCH $(1,1)$ model i.e. the inability of GARCH $(1,1)$ to properly describe the asymmetric property of most developing or transitional markets (Lux and Michele, 2005; Bauer, 2005). This finding is consistent with earlier evidence obtained by Kasch-Haroutounia and Price (2001). Their results suggest that the GJR-GARCH model is preferred to the alternate standard GARCH $(1,1)$ model in both cases. Alagidede and Panagiotidis (2006) used both daily and monthly stock data to examine the Ghana Stock Exchange. They employed the nonlinear models from the GARCH family in a rolling framework to investigate the role of asymmetry. The study gave GJR-GARCH a clear lead over other rivals. While GJRGARCH model may have proved successful for the two mentioned works, it turns out that it failed in other empirical investigations. Whereas, Piesse and Hearn (2002) studying African markets including Ghana, suggested Exponential GARCH (E-GARCH), another asymmetric model, evidence from Frimpong and Oteng-Abaiye (2006) on the same Ghana equity market inferred a different opinion of an appropriate model to fit the data. The result revealed that long memory was detected in the series and high persistence of the parameters of GARCH $(1,1)$ whose sum was very close to unity. This must have informed the choice of selecting the fractional integrated GARCH (FIGARCH) model as the most appropriate representation. Lamoureux and Lastrapes (1990) and Hillebrand (2005) attributed this high persistence to structural break 
in the data generating process.

The empirical successes and acceptance of the GARCH models in fitting volatility of stock returns notwithstanding, Udo (2000) warned that one should not be overtly optimistic about its forecasting results especially regarding the out-of-sample forecasting performance. This assertion seems to agree with empirical evidence by Zivot (2008) that the GARCH models do not forecast very well. Udo (2000) and Zivot (2008)s conjectures clearly provide enough ground to justify Ricardo (2000) and Brailsford and Faff (1999) views. They compared the complicated GARCH models with simpler alternative models using the Austrian stock market. The results in their papers indicate that no single model is clearly superior. The above recognition, perhaps, may have constrained the likes of Engel et al (2005) and Gujarati (2004) to admit that modeling is a probabilistic process. Consequently, some models tend to perform better in some periods and worse in other periods.

\section{Methodology}

The data analyzed in this study were obtained from the zonal office of the Nigerian Stock Exchange, Abuja, and they were 1239 daily closing prices of each of the two companys shares listed in the Exchange. The daily closing prices spanned from 2nd January, 2002 to 31st December, 2006. These companies are Guiness Plc. and First Bank of Nigeria being the most active in terms of per day number of deals and volume of transactions recorded during the period under review. They were adjusted for dividend payment and rights issue. The Box and Jenkins (1976) algorithm was used in building our models since without any lost of generality, the GARCH $(1,1)$ model is a proper transformation of ARMA $(1,1)$ process. The procedure involves the following steps:

\subsection{Identification}

Under the identification stage, the following tasks were performed:

(i) The daily closing prices were converted to returns series by this simple operation

$$
r_{t}=\ln \left(\frac{P_{t}}{P_{t-1}}\right) * 100 .
$$

where $P_{t}$ and $P_{t-1}$ are current and previous stock prices for $t=1,2, \cdots, 1239$.

(ii) Stationarity of the return series was checked using unit root test.

(iii) The modified Lagrange Multiplier (LM) and Ljung-Box MQ (K) statistics were used to test for ARCH effects on the squared residuals of the regressed AR (p) process, since GARCH $(\mathrm{p}, \mathrm{q})$ model implies ARCH $(r=q+p)$ model. Under the null hypothesis that there is no ARCH effects $\left(\alpha_{1}=\cdots \alpha_{p}\right)$, the LM test statistic equal to $T R^{2}$ has asymptotic chi squared distribution with $\mathrm{p}$ degree of freedom.

(iv) Unlike previous related studies where autocorrelation function (ACF) and partial autocorrelation function (PACF) were calculated to determine the order of the models, this step was ignored since the order of our models are implied already. However, the correlogram was examined to determine which among the processes is suggestive.

\subsection{Estimation of the GARCH model}

The estimation of the model's parameters was implemented by using numerical maximization of Brendt, Hall, Hall and Hausman (BHHH)'s likelihood function's subroutine in E-view software. This was done recursively for all the models, while noting the number of iterations and speed of convergence.

\subsection{Diagnostic checking}

(i)The squared residuals of the fitted model were analyzed to ascertain their randomness.

(ii) No ARCH effects test was carried using the Lagrange Multiplier (LM) statistic.

\section{Forecasting}

For the purpose of forecasting volatility, the rolling window procedure was used to obtain 1-step-ahead volatility forecasts for all the remaining out-samples. Furthermore, the forecasting performance of the competing models were evaluated and compared through three different statistical error functions: root mean square error (RMAE), mean absolute error (MSE) and mean absolute percent error (MAPE) defined below:

$$
R M S E=\sqrt{\frac{\sum_{t=T+1}^{T+K}\left(\hat{\sigma}_{t}-\sigma_{t}\right)^{2}}{K}}
$$




$$
\begin{gathered}
M A E=\frac{\sum_{t=T+1}^{T+K}\left|\hat{\sigma}_{t}-\sigma_{t}\right|}{K} \\
M A P E=\frac{100}{K} \sum_{t=T+1}^{T+K}\left|\frac{\hat{\sigma}_{t}-\sigma_{t}}{\sigma_{t}}\right|
\end{gathered}
$$

where $\mathrm{K}$ is the number of steps ahead, $\mathrm{T}$ is the sample size, $\hat{\sigma}_{t}$ and $\sigma_{t}$ are the square root of the conditional forecasted volatility and the realized volatility respectively. The model which yields the lowest values of the forecast evaluation statistics we have highlighted is adjudged the most fitting model.

\section{Results}

The time plots of the daily closing prices of the company whose shares are analyzed are presented in figures 1, 2, 3 and 4 below. From the swings of each plot it is very clear that

[Fig.s 1 - 8]

stock closing prices in their level form are very irregular with varied degree of fluctuations. The graphs could best be described as being non-stationary, piecewise periodic process with varying amplitude. Unstable series such as these cannot be used for further statistical inferences because of their grave implications (Gujarati, 2004). Consequently, the need to transform them to returns. The plots of daily returns of Guiness, UBA, Unilever, and Mobil are presented in figures 5, 6, 7 and 8 respectively. Unlike the plots of closing prices, the plots for returns are not only stationary but trendless with varied amplitude over time. Engle (2001) interpreted this as the presence of ARCH effects. Also, there are marked periods of calmness interjected with turbulence. A phenomenon otherwise referred in finance as volatility clustering. This is very conspicuous in all the plots.

Table 1 gives a glaring result of the stationary check for both closing prices and returns using Philip Perron (PP) and Augmented Dickey Fuller (ADF) test statistics respectively. Under the null hypothesis, unit root is detected in stock closing prices while both tests failed for returns.

[Table 1]

In Table 2, a wide range of descriptive statistics for the return series of the four equities is reported. The values of standard deviation for each of the series are closed with Unilever being more volatile. All return show evidence of heavy but left tails, and extremely high leptokurtic values, corroborating previous findings that stock returns are not normally distributed. The Jarque-Berra test leads to the same rejection of normality in any of the series.

The autocorrelations with their respective Ljung-Box test statistic in returns and its corresponding squared are all positive and significant at all lags. This confirms the earlier evidence of GARCH presence detected in the plots and provides justifiable grounds to reject the twin hypotheses of no GARCH effects and zero serial correlation in return series. This finding however, do not agreed with an earlier result obtained by Haque et al (2004), who investigated the stocks volatility of ten economies in African Equities Markets and found no volatility clustering in the Nigerian and Oman stock markets at all.

[Table 2]

The symbol MQ (K) denotes Modified Ljung-Box test statistic in returns series for $5^{\text {th }}, 24^{\text {th }}$ and $60^{\text {th }}$ lags whereas $M Q^{2}(K)$ denotes Modified Ljung- Box test statistic in squared returns series for $24^{\text {th }}$ and $60^{\text {th }}$ lags.

Table 4.5 below presents the maximum likelihood estimation results for $\operatorname{GARCH}(1,1)$, GJR-GARCH $(1,1)$ and EGARCH $(1,1)$ for the parameter estimates of the four equities considered in this thesis assuming a Gaussian distribution. The conditional variance estimates of GARCH $(1,1)$ are significant and statistically different from zero. They are all positive values except for Unilever that they are negative values for $\alpha_{1}$ in both $\operatorname{GARCH}(1,1)$ and GJR-GARCH $(1,1)$ models. The estimate of $\beta_{1}$ clearly dominates others in each of the series.

The estimates of the leverage effect $(\gamma)$ in each of the asymmetric models though are very significant give different results across the series. Under the EGARCH $(1,1)$ model, the estimates of $\gamma$ are highly significant at $5 \%$ or $10 \%$ level but have 
positive coefficients throughout except otherwise in Guiness. These results are inconsistent with the conventional situation where negative signs are assumed for leverage effect presence, therefore, Guiness is the only series where volatility can be said to be negatively correlated with return as far the EGARCH models is concerned. The case is however, different for GJR-GARCH $(1,1)$ model. The coefficients of the estimates are all positive except for Mobil where a negative value turns out. In other words, leverage effect is found in all the series apart from Mobil on the application of GJR-GARCH $(1,1)$, and for the two asymmetric models, leverage effect is truly observed only in Guiness series.

The test for covariance stationary and stability condition reported in Egert and Koubaa (2004) as $\alpha_{1}+\beta_{1} \leq 1$ for GARCH $(1,1), \alpha_{1}+\beta_{1}+\left(\frac{\gamma}{2}\right) \leq 1$ for its EGARCH $(1,1)$ counterpart and $\beta_{1}+\frac{\alpha_{1}+\gamma_{1}}{2} \leq 1$ for $\operatorname{GJR}-\operatorname{GARCH}(1,1)$ are satisfied in some series while in other cases the constraint is violated. The closer the sum $\alpha_{1}+\beta_{1}$ tends to unity, the more persistence volatility becomes. Using GJR-GARCH $(1,1)$, the covariance stationarity condition is satisfied in all the series, while in the GARCH $(1,1)$ model, the constraint is violated only in Guiness, while in EGARCH $(1,1)$ model, the condition is violated for UBA, Guiness and Mobil. The implication of such violations is not trivial, to say the least. According to Akigray (1989), processes where the covariance stationarity condition is not satisfied will produce less reliable forecasts. Based on this, the GJR-GARCH $(1,1)$ model is tentatively suspected to provide satisfactory fitting among its revivals to the return of the equities under consideration.

\subsection{Model selection}

The results of in-sample goodness-of- fit and residuals analysis are presented in table 4 . The excess kurtoses of the residuals have dropped down, especially in the asymmetry models except for the Mobil and UBA series. The log-likelihood estimates are all negative values as they are ought to be, and Akaike information measure are compared to select among the competing models the least value in each series. Taking altogether the results of covariance stationarity tests with the Akaike information measure (AIM), GJR-GARCH $(1,1)$ model is selected for UBA, Unilever and Guiness series, and GARCH $(1,1)$ model for Mobil series respectively. These results further confirm the earlier suspicion that GJR-GARCH $(1,1)$ model is most preferred among its rivals to give satisfactory fitting to the data of the Nigerian Stock Market.

[Table 3]

\subsection{Diagnostic check}

The adequacy of the selected models is done so that any misspecification error is detected. The result of the correleograms for squared standardized residuals is examined for autocorrelations. As $7^{\text {th }}$ and $8^{\text {th }}$ columns of Table 4 show, the autocorrelations and partial autocorrelations with their respective Modified ljung-Box test statistic have reduced dramatically from those observed in Table 2 and none is individually statistically significant. Technically speaking, the residuals from the estimated models are purely random. In addition to the above test whose p-values are above 0.5 , the Lagrange multiplier test (not reported) fails to reject "no GARCH effects" in the residuals. The conclusion drawn from these results is that the GARCH models considered in this debate are all adequate for describing the volatility of the Nigerian Stock Market.

[Table 4]

\section{Forecasting}

The main emphasis of this study is limited to the task of modeling. However, since forecasting is the prime object of modeling, volatility forecasts of the series based on the models chosen by the prescribed forecasting performance error functions, are generated graphically below.

[Fig.s 4.4a - 4.4d]

\subsection{Volatility forecast performance}

The results of volatility forecasts performance and evaluations are reported in table 4.7. The statistics for accomplishing this are already enumerated in section 3.8. They include Root Mean Squared Error (RMSE), Mean Absolute Error (MAE) and Mean Absolute Percentage Error (MAPE). From the relative values reported in the table, the preference of one model to the other differs according to the series involved. 


\section{Conclusion}

The objectives of the study of this research work have been largely achieved. Returns series of firms whose share prices were analyzed reveal some stylized facts such as negative skewness, leptokurtosis, and volatility clustering, nonlinear data generating process, serial dependence and leverage effects which are common observations in other stock markets. The presence of non zero serial correlation and significant level of second-order autocorrelations in the return series, confer evidence of predictability, though on shorter horizons. Since autocovariance stationary and stability condition are satisfied, the application of GARCH models in simulating returns data are not in doubt. The empirical results show that GJR-GARCH $(1,1)$ model significantly outperforms other heteroscedastic models used in the study according to both insamples Akaike information criterion and out-samples statistical error metrics. The estimated models show high volatility persistence suggesting good opportunity for investors and speculators to take advantage of in the tradeoff between risk and returns in the Nigeria capital market.

\section{References}

Akigray, V. (1989). Conditional Heteroscedasity in Time tock of Stock Returns: Evidence and Forecasting. Journal of Busineness, 62, 55 - 80.

Alagidede, P. and Panagiotidis, T. (2006). Calendar Anomaly in an emerging African Market. Evidence from Ghana Stock Exchange. Discussion Paper, Economics Department, Southborough University (unpublished).

Ann-Sing, C. and Mark, L. (2005). Modeling Time Series Information into Optical Prices: An Empirical Evaluation of Statistical Projection and GARCH Options Pricing Models. Elsevier, Amsterdam, North Holland.

Baillie, R. T. and Mikkelsen, B. T. (1996). Fractionally Integrated Generalized Autoregressive Conditional Heteroscedasticity. Journal of Econometrics, 74, 3 - 30. http://dx.doi.org/10.1016/S0304-4076(95)01749-6

Bauer, C. (2005). A Better Asymmetric Model of Changing Volatility in Stock Returns. Quantitative Finance, ISSN 1611-3837.

Black, F. and Scholes, M. (1975). Asset Speculative Prices. Journal of Business, 7, 307 - 324.

Brailsford, A. and Faff, M. D. (1999). An Evaluation of Volatility Forecasting Technique of Banking and Finance. 419438.

Bollerslev, T. (1986). Generalized Autoregressive Conditional Heteroscedasticity. Journal of Econometrics, 31, 307 327. http://dx.doi.org/10.1016/0304-4076(86)90063-1

Box and Jenkins. (1976). Time Series Analysis and Control, 2nd ed. Holden Day, San Francisco.

Egert, B. and Koubaa, Y. (2004). Modeling Stock Returns in the G-7 and in Selected Central and Eastern European Economies: A Nonlinear GARCH Approach. William Davidson Institute Working Paper No. 663 University of Michigan Business School.

Engle, R. and Ng, V. (1998). Measuring and Testing the Impact News on Volatility. Journal of Finance, 48, 1748 - 1778.

Engle, R. F. and Patton, A. J. (2000). What is Volatility Models? Manuscript of University of Stern, New York. http://www.stern.nyu.edu./ rengle/paper/vol.pdf.

Engle, R. F. (2001). The Use of ARCH/GARCH Models in Applied Economics. Journal of Economics Perspective, 15, 157 - 168. http://dx.doi.org/10.1257/jep.15.4.157

Engle, R. F., Forcard, S. M. and Fabozzi, F. (2005). ARCH/GARCH Models in Applied Financial Econometrics. Journal of Econometrics and Financial, Chapter 60, 4, 109 - 133.

Franses, P. H. and Djik, V. D. (1998). Forecasting Stock Market Volatility Using Nonlinear GARCH. Journal of Forecasting, 1, No.15, 229 - 235 .

Franses, P. H. and Djik, V. D. (2000). Nonlinear Time Series Models in Emprical Financial. Cambridge University Pres, Cambridge. http://ideas.respec.org/a/eee/intfor/s-752html.

Frimpong, J. M. and Oteng-Abaiye, E. (2006). Modeling and Forecasting Volatility of Returns on the Ghana Stock Exchange Using GARCH Models MPRA Paper No. 593. http://www.mpra.ub.uni.muenchen.de/593/.

Glosten, J. and Runkle (1993). On the Relationship Between the Expected value and of Nominal Excess Return on Stocks. Journal of Finance, 46, 1749 - 1801.

Gujarati, D. N. (2004). Basic Econometrics. 4th ed. Tata McGraw-Hill Publishing Company Limited, New Delhi, India. Hansen, P. R. and Lunde (2001). A Forecast Comparison of Volatility Models: Does Anything Beat a GARCH $(1,1)$. 
Mimeo, Brown University.

Haque, M., Hassan, M. K., Maroney, N. C. and Sackley, W. H. (2004). An Empirical Examination of Stability, Predictability and Volatility of Middle Eastern and African Emerging Stock Markets. Reviews of Middle East Economics and Finance, 2, 19 - 42. http://dx.doi.org/10.1080/14753680410001685669

Hillebrand , E. (2005). Neglecting Parameters Change in GARCH Models. Journal of Econometrics, 12,121 - 138. http://dx.doi.org/10.1016/j.jeconom.2004.09.005

Hongyu, P. and Zhichao, Z. (2006). Forecasting Financial Volatility: Evidence from Chinese Stock Market. Working paper in Economics and Finance Conference, 2, 63 - 86.

Kasch-Haroutounia, M and Price, S. (2001). Volatility in Transitional Markets of Central Europe. Applied Financial Economics, 11, 93 - 105. http://dx.doi.org/10.1080/09603100150210309

Lamoureux, C. G. and Lastrapes, W. D. (1990). Heteroscedasticity in Stock Returns Data. Volume versus GARCH Effects. Journal of Economic Survey, 7, 82 - 85.

Laurent, S. and Peters, J. (2002). Tutorial for GARCH 2.3. A Complete OX Package for Estimating and Forecasting ARCH Models. Journal of Economic Survey, 4, 25 - 36.y

Lux, T. and Michele, M. (2005). Volatility Clustering in Financial Markets: A Micro Simulation of Intracting Agents. International Journal of Theoretical and Applied Finance.

McMillian, S. and Gwilym, M. (2000). Forecasting United Kingdom Stock Markets Volatility. Applied Financial Economics, 57, $438-448$.

Najand, M. (2002). Forecasting Stock Index Future Volatility: Linear Versus Nonlinear Models. The Financial Reviews, 37, 93 - 100. http://dx.doi.org/10.1111/1540-6288.00006

Nelson, D. B. (1991). Conditional Heteroscedasticity in Asset Returns: A new Approach. Econometrica, 41,1176 - 1179.

Piesse, J. and Hearn, B. (2002). Equity Market Integration Versus Segmentation in Three Dormant Markets of the South African Custom Union. Journal of Applied Economics, 5, 132 - 155.

Poon, S. H. and Granger. C. W.J. (2003). Forecasting Financial Volatility. Journal of Economic Literature, 41,478 - 539. http://dx.doi.org/10.1257/002205103765762743

Poshakwale, S. and Murinde. (2001). Modeling the volatility in Eastern European Emerging Stock Markets; Evidence on Poland and Hungary. Applied Financial Economics, 11, 445 - 456. http://dx.doi.org/10.1080/096031001300314009

Ricardo, S. (2000). Reality Check for Volatility Models. Lecture Notes of Department of Economics and Finance. University of California, San Diego. http://www.weber.ucsd.edu /econs508/ note580.

Udo, S. (2000). Volatility Forecasting with Nonlinear and Linear Time series Models: A Comparison. Financial Analyst Journal, 18, 1109 - 1119.

Wagle, G. (2008). Financial Forecasting and Volatility Models. Unpublished Master Degree Thesis, Department of Computer Science and Engineering, India Institute of Technology, Mumbai.

Zakoian, J. (1994). Threshold tic Function. Journal of Economic Dynamics and Control, 18, 931 - 955. http://dx.doi.org/10. 1016/0165-1889(94)90039-6

Zhang, J. and Wirjanto. T. (2006). Modeling and Forecasting Volatility in China's Stock Markets. Journal of Chinese Economic and Business Studies, 7, 307 - 324.

Zivot, E. (2008). Practical Issues in the Analysis of Univariate GARCH Models. John Wiley, New York.

Table 1. Unit root testing for daily return and closing prices

\begin{tabular}{|c|c|c|c|c|c|c|c|}
\hline \multirow{2}{*}{ FIRM } & \multicolumn{3}{|c|}{ Daily returns } & \multicolumn{3}{c|}{ Daily closing prices } & \multirow{2}{*}{$\begin{array}{c}\text { Mackinnon } \\
\end{array}$} \\
\cline { 2 - 7 } & ADF & PP & P-value & ADF & PP & P-value & (5\% C.R.) \\
\hline Guiness & -30.732 & -31.243 & 0.00 & -2.005 & -2.202 & 0.2850 & -2.8637 \\
\hline Mobil Oil & -34.826 & -35.985 & 0.00 & -1.445 & -1.153 & 0.5461 & -2.8637 \\
\hline UBA & -30.708 & -30.439 & 0.00 & 0.137 & 0.3098 & 0.9682 & -2.8637 \\
\hline Unilever & -34.395 & -34.863 & 0.00 & -2.994 & -2.884 & 0.0358 & -2.8644 \\
\hline
\end{tabular}


Table 2. Descriptive statistics of the series

\begin{tabular}{|c|c|c|c|c|c|c|c|c|c|c|c|c|c|}
\hline FIRM & Samp Size & Max. & Min. & Mean & Std & Skew & Kurtosis & Jarque/Berra & MQ(5) & MQ(24) & $\mathrm{MQ}(60)$ & $M Q^{2}(24)$ & $M Q^{2}(60)$ \\
\hline Guiness & 1239 & 158.8 & -25.2 & 0.04 & 1.3 & -6.23 & 117.7 & 686238 & 43.35 & 75.80 & 122.6 & 308 & 308 \\
\hline Mobile & 1239 & 4.21 & -10.9 & 0.04 & 1.1 & -0.84 & 11.8 & 4124.14 & 19.99 & 43.25 & 74.84 & 124 & 185 \\
\hline UBA & 1239 & 0.29 & -18.9 & 0.29 & 1.3 & -1.88 & 47.1 & 13.578 & 50.07 & 72.79 & 117.7 & 234 & 285 \\
\hline Unilever & 1239 & 4.62 & -39.8 & -0.27 & 1.6 & -11.7 & 281.6 & 4031711 & 13.09 & 28.75 & 56.38 & 126 & 225 \\
\hline
\end{tabular}

Table 3. Maximum likelihood estimates of GARCH models

\begin{tabular}{|c|c|c|c|c|c|c|}
\hline \multirow[b]{2}{*}{ Equity } & \multirow[b]{2}{*}{ Model } & \multirow[b]{2}{*}{$(\mathrm{p}, \mathrm{q})$} & \multicolumn{4}{|c|}{ Parameters } \\
\hline & & & $\omega$ & $\alpha_{1}$ & $\beta_{1}$ & $\gamma$ \\
\hline \multirow{3}{*}{ UBA } & GARCH & $(1,1)$ & $\begin{array}{c}0.309009 \\
(0.021468)\end{array}$ & $\begin{array}{c}0.250113 \\
(0.020577)\end{array}$ & $\begin{array}{c}0.619666 \\
(0.024104)\end{array}$ & \\
\hline & GJR-GARCH & $(1,1)$ & $\begin{array}{c}0.324696 \\
(0.031641)\end{array}$ & $\begin{array}{c}0.208304 \\
(0.065848)\end{array}$ & $\begin{array}{l}0.60614 \\
(0.0376)\end{array}$ & $\begin{array}{c}0.094731 \\
(0.053539)\end{array}$ \\
\hline & EGARCH & $(1,1)$ & $\begin{array}{l}-0.064938 \\
(0.015725)\end{array}$ & $\begin{array}{c}0.268703 \\
(0.039329)\end{array}$ & $\begin{array}{c}0.762631 \\
(0.026348)\end{array}$ & $\begin{array}{c}0.052933 \\
(0.024192)\end{array}$ \\
\hline \multirow{3}{*}{ Guiness } & GARCH & $(1,1)$ & $\begin{array}{c}0.22114 \\
(0.05685)\end{array}$ & $\begin{array}{c}0.66665 \\
(0.040412)\end{array}$ & $\begin{array}{c}0.403451 \\
(0.036939)\end{array}$ & \\
\hline & GJR-GARCH & $(1,1)$ & $\begin{array}{c}0.23769 \\
(0.02683)\end{array}$ & $\begin{array}{c}0.44466 \\
(0.06841)\end{array}$ & $\begin{array}{c}0.39418 \\
(0.03782)\end{array}$ & $\begin{array}{c}0.41988 \\
(0.06564)\end{array}$ \\
\hline & EGARCH & $(1,1)$ & $\begin{array}{l}-0.447581 \\
(0.033174)\end{array}$ & $\begin{array}{c}0.717529 \\
(0.052348)\end{array}$ & $\begin{array}{l}0.775895 \\
(0.02271)\end{array}$ & $\begin{array}{c}-0.13398 \\
(0.024934)\end{array}$ \\
\hline \multirow{3}{*}{ Mobil } & GARCH & $(1,1)$ & $\begin{array}{c}0.347399 \\
(0.074758)\end{array}$ & $\begin{array}{c}0.13418 \\
(0.038117)\end{array}$ & $\begin{array}{c}0.579008 \\
(0.090647)\end{array}$ & \\
\hline & GJR-GARCH & $(1,1)$ & $\begin{array}{c}0.342172 \\
(0.075557)\end{array}$ & $\begin{array}{c}0.136975 \\
(0.047401)\end{array}$ & $\begin{array}{c}0.585345 \\
(0.091306)\end{array}$ & $\begin{array}{l}-0.010279 \\
(0.051601)\end{array}$ \\
\hline & EGARCH & $(1,1)$ & $\begin{array}{l}-0.029012 \\
(0.005741)\end{array}$ & $\begin{array}{c}0.052102 \\
(0.0011344)\end{array}$ & $\begin{array}{l}0.960371 \\
(0.01026)\end{array}$ & $\begin{array}{c}0.039635 \\
(0.015344)\end{array}$ \\
\hline \multirow{3}{*}{ Unilever } & GARCH & $(1,1)$ & $\begin{array}{c}0.134745 \\
(0.078139)\end{array}$ & $\begin{array}{l}-0.007735 \\
(0.000649)\end{array}$ & $\begin{array}{l}0.951581 \\
(0.02918)\end{array}$ & \\
\hline & GJR-GARCH & $(1,1)$ & $\begin{array}{c}0.224319 \\
(0.052567)\end{array}$ & $\begin{array}{l}-0.072328 \\
(0.006759)\end{array}$ & $\begin{array}{c}0.936809 \\
(0.019329)\end{array}$ & $\begin{array}{c}0.071939 \\
(0.007019)\end{array}$ \\
\hline & EGARCH & $(1,1)$ & $\begin{array}{c}0.897123 \\
(0.147571)\end{array}$ & $\begin{array}{c}0.357733 \\
(0.080165)\end{array}$ & $\begin{array}{l}-0.164396 \\
(0.144365)\end{array}$ & $\begin{array}{c}0.347376 \\
(0.050612)\end{array}$ \\
\hline
\end{tabular}

The standard errors are in paranthesis.

Table 4. ln-Sample model selection criteria for GARCH estimates

\begin{tabular}{|c|c|c|c|c|c|c|c|c|}
\hline \multirow{3}{*}{ Equity } & & & \multicolumn{7}{|c|}{ Daignostic Analysis } \\
\cline { 4 - 9 } & Model & $(\mathrm{p}, \mathrm{q})$ & $\log (\mathrm{L})$ & $\mathrm{AIM}$ & $M Q_{1}(10)$ & $M Q_{2}(10)$ & Kurtosis & JB \\
\hline \multirow{3}{*}{ UBA } & GARCH & $(1,1)$ & -2014.457 & 3.26084 & 26.211 & 0.234 & 53.85 & 133850 \\
\cline { 2 - 9 } & GJR-GARCH & $(1,1)$ & -2013.31 & 3.26 & 27.75 & 0.22 & 51.56 & 121980 \\
\cline { 2 - 9 } & EGARCH & $(1,1)$ & -2029.21 & 3.28627 & 37.59 & 0.12 & 51.56 & 121980 \\
\hline \multirow{3}{*}{ Mobiness } & GARCH & $(1,1)$ & -1844.001 & 2.98546 & 27.00 & 0.88 & 28.297 & 33753 \\
\cline { 2 - 9 } & GJR-GARCH & $(1,1)$ & -1835.42 & 2.97321 & 27.91 & 1.29 & 21.51 & 18085 \\
\cline { 2 - 9 } & EGARCH & $(1,1)$ & -1856.736 & 3.00765 & 27.51 & 0.82 & 26.94 & 30172 \\
\hline \multirow{3}{*}{ Unileveryyyyyyyy} & GJR-GARCH & $(1,1)$ & -1834.831 & 2.97065 & 21.85 & 0.31 & 18.61 & 12946 \\
\cline { 2 - 9 } & EGARCH & $(1,1)$ & -1834.81 & 2.97223 & 21.97 & 0.311 & 18.66 & 13021 \\
\cline { 2 - 9 } & GJR-GARCH & $(1,1)$ & -1834.59 & 2.97188 & 24.91 & 1.73 & 17.83 & 11654 \\
\cline { 2 - 9 } & EGARCH & $(1,1)$ & -2359.37 & 3.81804 & 22.18 & 0.04 & 274.75 & 3836498 \\
\hline
\end{tabular}


Table 5. Forecast performance of estimated models

\begin{tabular}{|c|c|c|c|c|}
\hline Equity & Statistic & GARCH & EGARCH & GJR-GARCH \\
\hline \multirow{3}{*}{ UBA } & RMSE & $1.325953^{(1)}$ & $1.326102^{(3)}$ & $1.325961^{(2)}$ \\
\cline { 2 - 5 } & MAE & $0.826696^{(2)}$ & $0.836102^{(3)}$ & $0.823526^{(1)}$ \\
\cline { 2 - 5 } & MAPE & $81.44448^{(2)}$ & $86.56687^{(3)}$ & $80.70825^{(1)}$ \\
\hline \multirow{3}{*}{ Mobil } & RMSE & $1.087432^{(2)}$ & $1.087449^{(3)}$ & $1.087431^{(1)}$ \\
\cline { 2 - 5 } & MAE & $0.73701^{(1)}$ & $0.738548^{(3)}$ & $0.737339^{(2)}$ \\
\cline { 2 - 5 } & MAPE & $115.0467^{(1)}$ & $124.5937^{(3)}$ & $117.0878^{(2)}$ \\
\hline \multirow{3}{*}{ Unilever } & RMSE & $1.639324^{(1)}$ & $1.644921^{(3)}$ & $1.639328^{(2)}$ \\
\cline { 2 - 5 } & MAE & $0.896734^{(1)}$ & $0.920954^{(3)}$ & $0.897649^{(2)}$ \\
\cline { 2 - 5 } & MAPE & $90.47607^{(1)}$ & $122.3435^{(3)}$ & $91.31432^{(2)}$ \\
\hline & RMSE & $1.309544^{(3)}$ & $1.308776^{(2)}$ & $1.308436^{(1)}$ \\
\cline { 2 - 5 } & MAE & $0.787123^{(3)}$ & $0.783521^{(2)}$ & $0.780262^{(1)}$ \\
\cline { 2 - 5 } & MAPE & $146.7667^{(3)}$ & $129.4664^{(2)}$ & $111.8679^{(1)}$ \\
\hline
\end{tabular}

The models are ranked by their superscripted numbers in paranthesis.

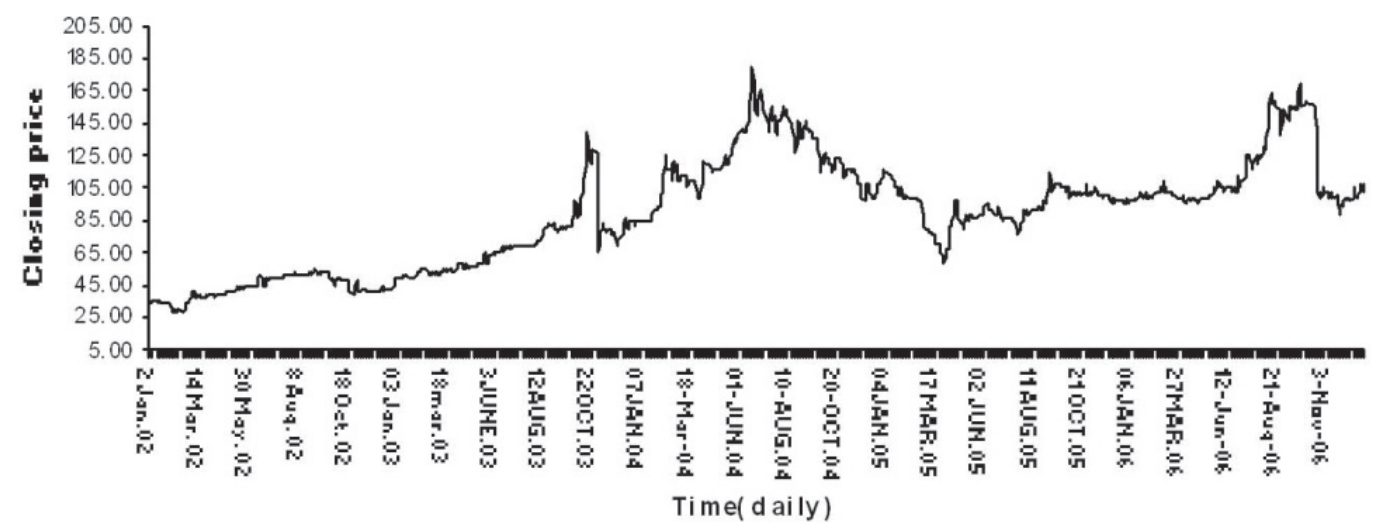

Figure 1. Time plot of daily closing price for Guiness Nig. PLC

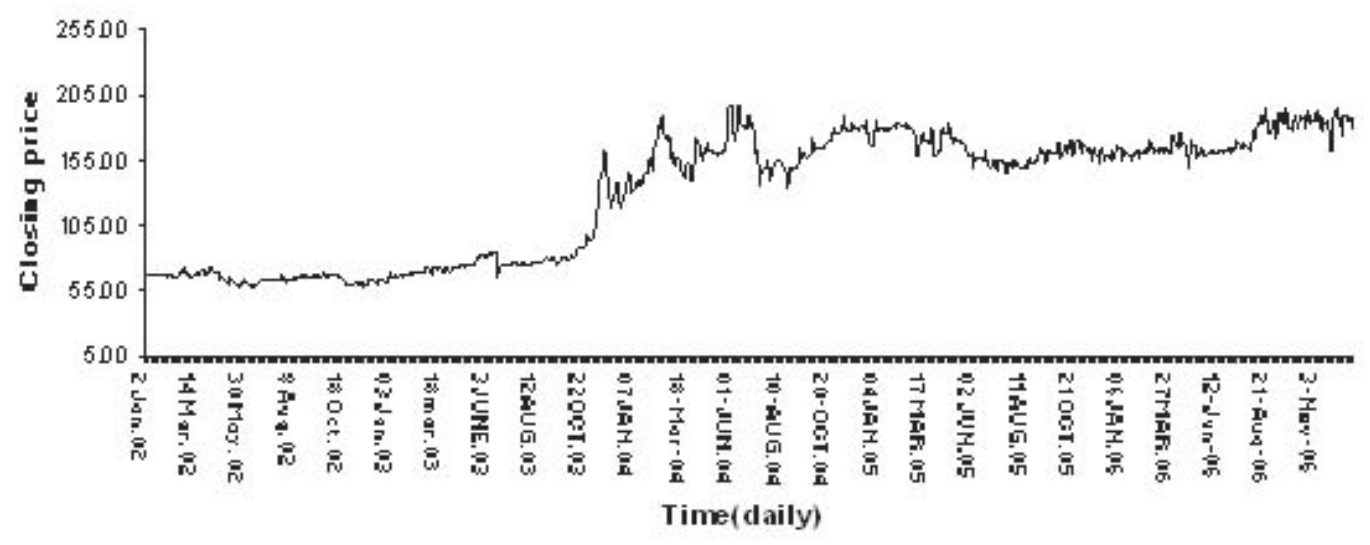

Figure 2. Time Plot of daily closing price for Mobil oil Nig. PLC 


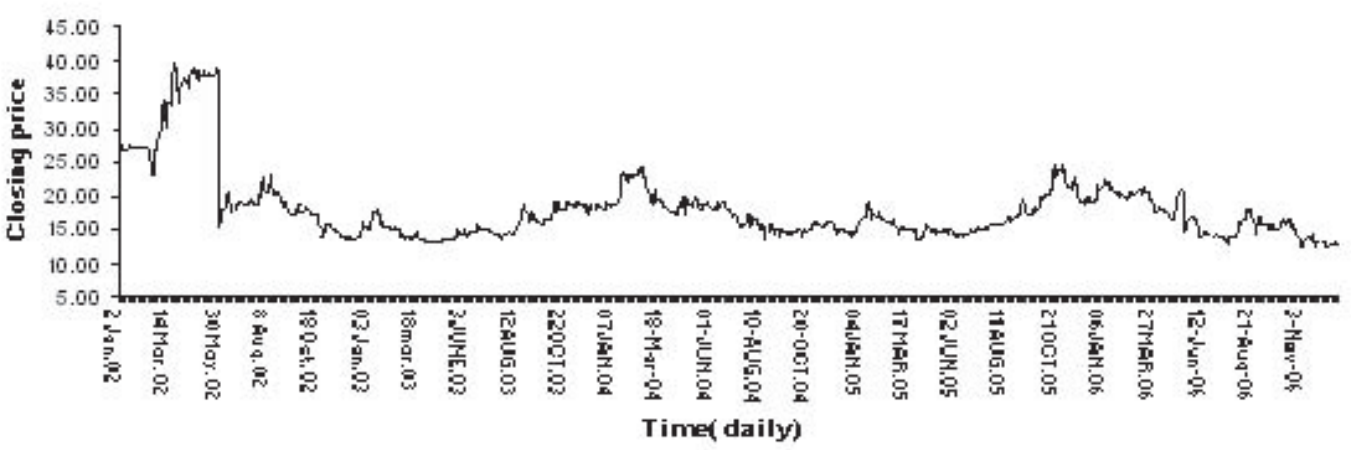

Figure 3. Time plot of daily closing price for Unilever Nig. PLC

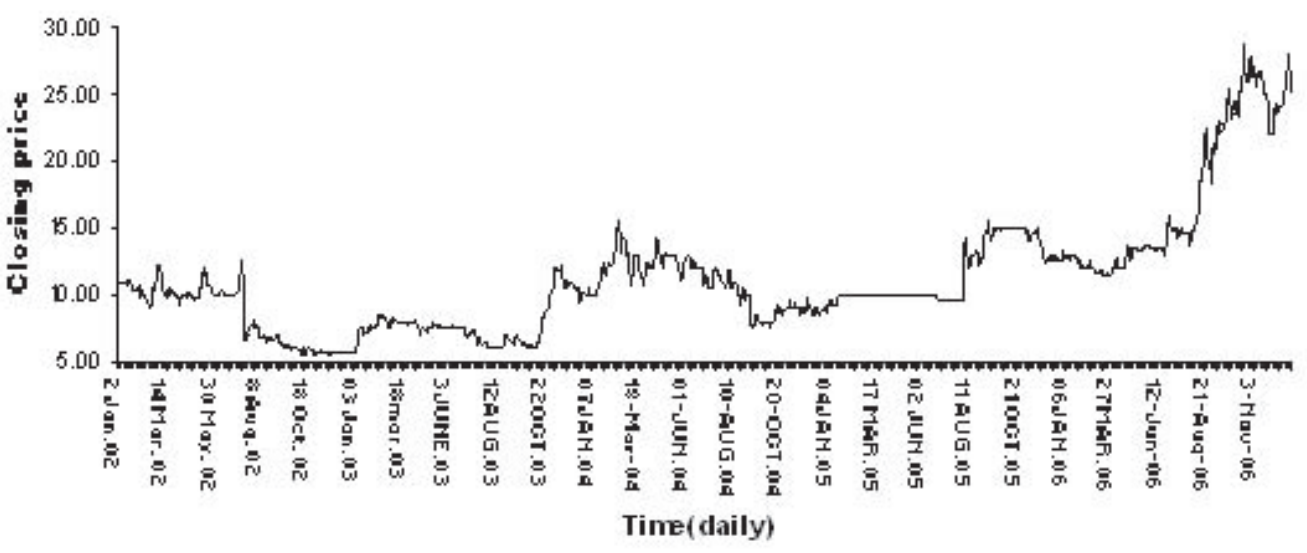

Fig. 4.4a: G.JR-GA RCH (1,1) FOR UBA

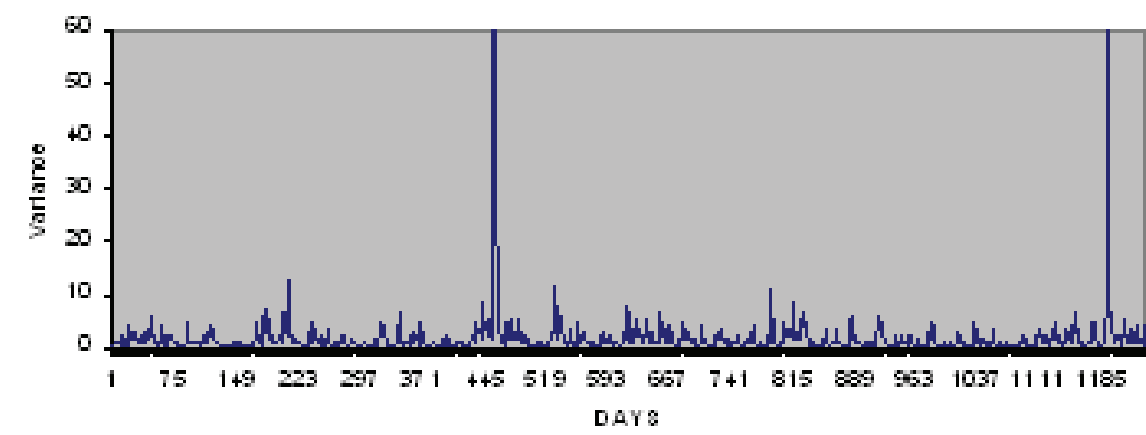

FIgA Ab: GARCH (1,1) for mobll

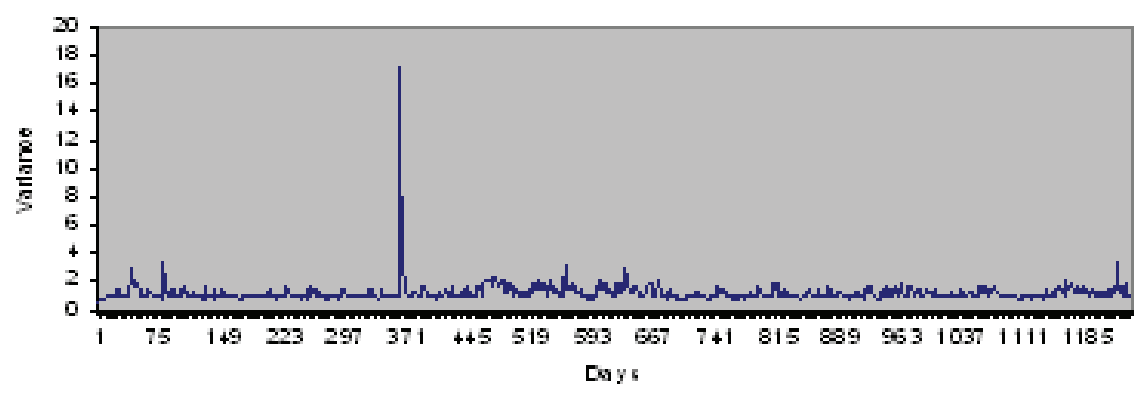



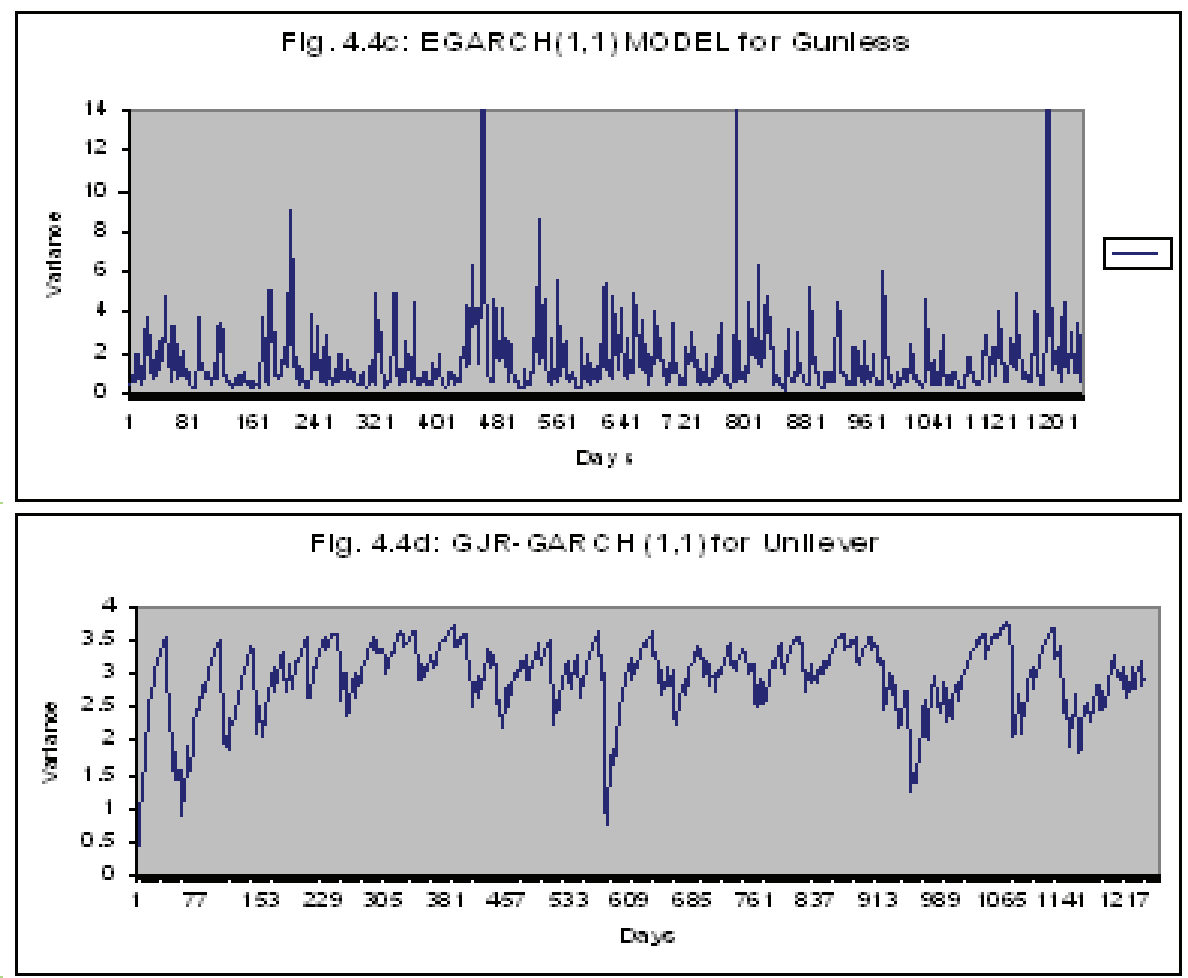

Figure 4. Time plot of daily closing price for UBA Nig. PLC

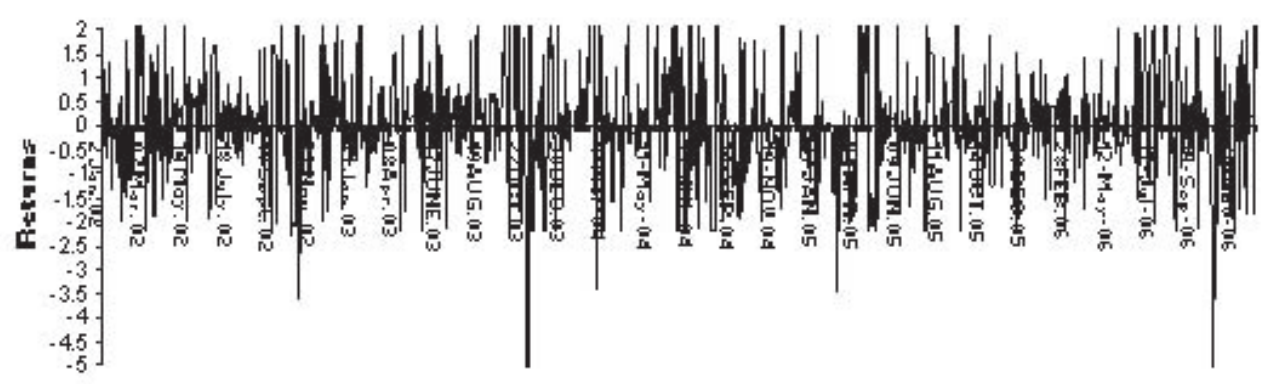

Ti me(daily)

Figure 5. Time plot of daily Returns for Guiness Nig. PLC

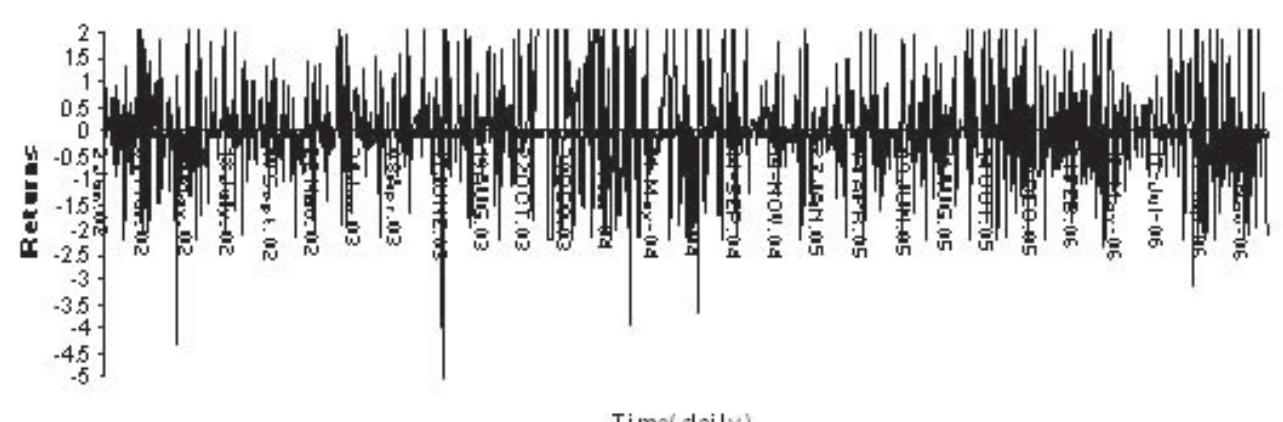

Figure 6. Time plot of daily Returns for Mobil oil Nig. PLC 


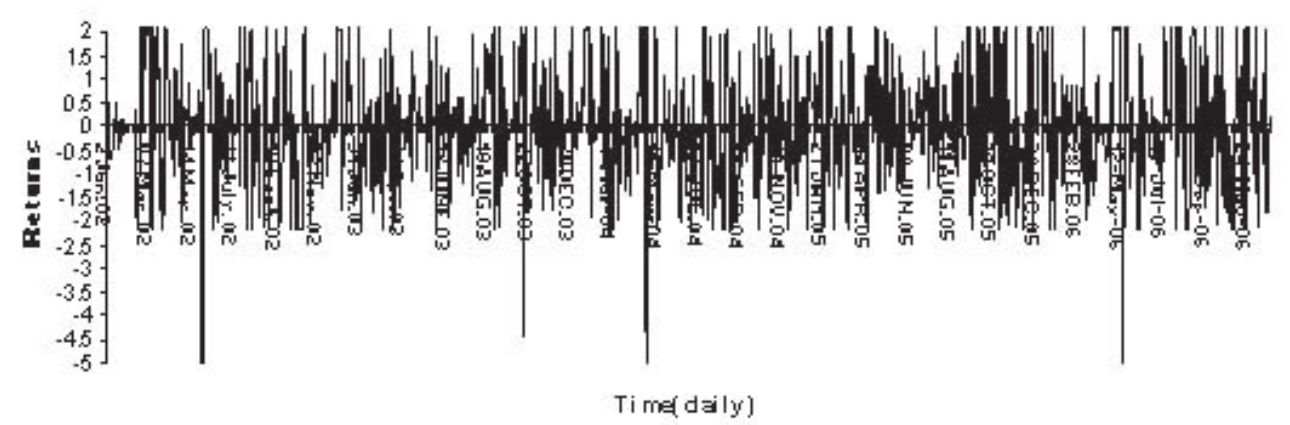

Figure 7. Time plot of daily Returns for Unilever Nig. PLC

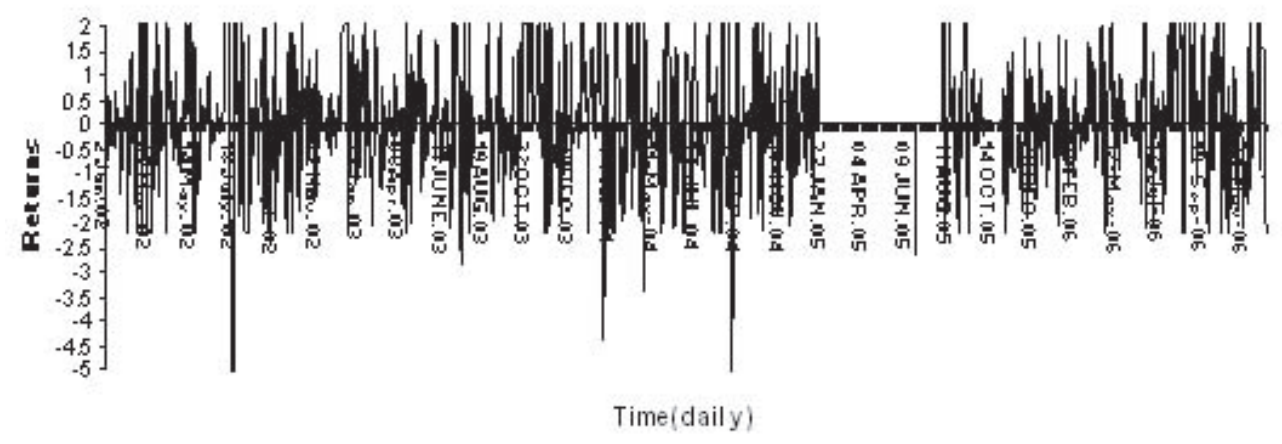

Figure 8. Time plot of daily Returns for UBA Nig. PLC 